\title{
A hypertrophic senile heart
}

\author{
I. Arts-Birstonaite · J. Jaspers Focks · C. Camaro · R. Nijveldt
}

Published online: 5 February 2020

(C) The Author(s) 2020
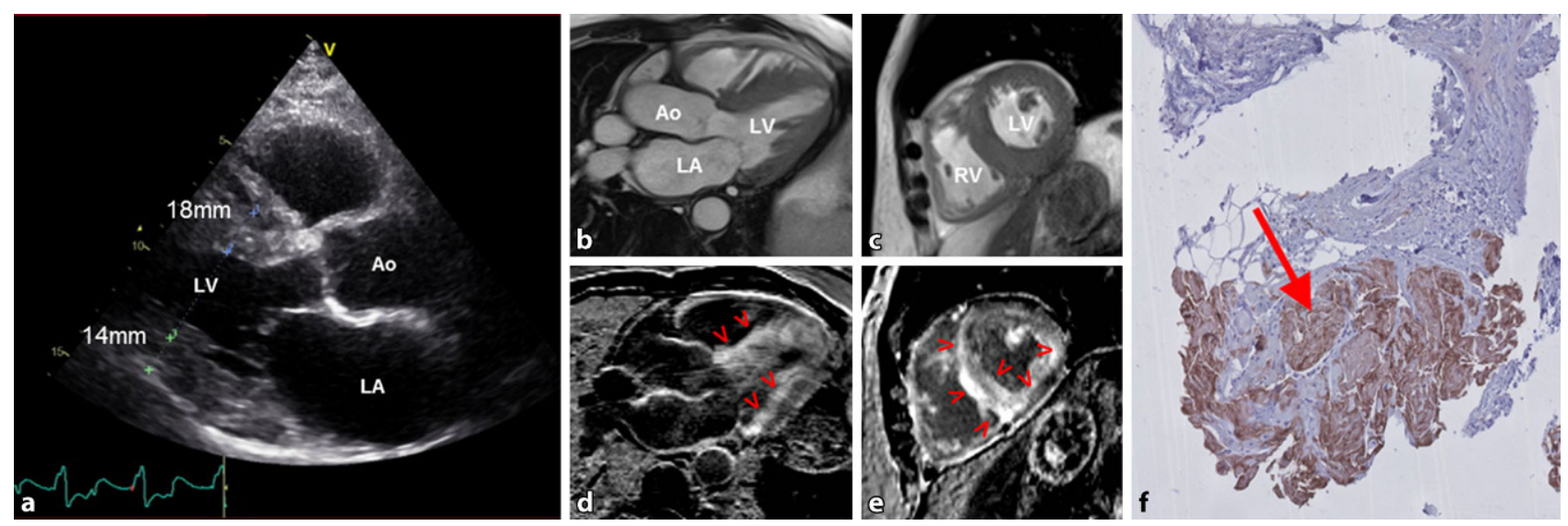

Fig. 1 Echocardiographic parasternal long axis view with hypertrophic interventricular septum $(18 \mathrm{~mm})$ and posterior wall $(14 \mathrm{~mm})$ of the left ventricle (a). CMR cine images demonstrated thickened myocardium on the 3-chamber (b) and midventricular short axis (c) views, with the corresponding late gadolinium enhanced images $(\mathbf{d}, \mathbf{e})$ showing diffuse suben-

docardial contrast enhancement (red arrow heads). Light microscopy of the septal myocardial biopsy shows Congo red staining positive for amyloid (arrow). CMR cardiac magnetic resonance, $A$ o aorta, $L V$ left ventricle, $L A$ left atrium, $R V$ right ventricle

In this case report we describe a 77-year-old man with a history of bilateral carpal tunnel syndrome who presented with dyspnoea on exertion. The electrocardiogram showed low voltage QRS complexes, while echocardiography demonstrated prominent concentric hypertrophy of the left ventricle with speckled appearance of the myocardium (Fig. 1a). Coronary angiography revealed severe proximal left anterior descending artery stenosis for which intervention was performed. Since symptoms persisted, cardiac magnetic resonance imaging was performed for further evaluation (Fig. 1b, c). The proper late gadolinium

I. Arts-Birstonaite $(\bowtie) \cdot J$ J Jaspers Focks · C. Camaro · R. Nijveldt

Department of Cardiology, Radboud University Medical Center, Nijmegen, The Netherlands

ieva.arts@gmail.com enhancement (LGE) images were difficult to obtain due to the inability to suppress the signal of "normal' myocardium - a pathognomonic phenomenon for diffuse amyloid fibrils deposition in the whole myocardium (Fig. 1d, e). Endomyocardial biopsy verified the diagnosis of transthyretin cardiac amyloidosis (ATTR-CA) with Congo red staining of transthyretin fibrils (Fig. 1f).

ATTR-CA exists in mutated and wild-type (ATTRwt) amyloidosis. This type is underestimated among the elderly, especially in patients with aortic stenosis and secondary left ventricular hypertrophy [1]. Studies show its incidence of $25 \%$ in octogenarians [1]. In this case, the concomitant presence of carpal tunnel syndrome could have been a clue.

Besides supportive therapy with diuretics, tafamidis has recently been introduced. This benzoxazole 
derivate binds to transthyretin fibrils, preventing further dissociation to monomers and depositions in the myocardium. It is particularly effective in the early stage of disease (NYHA class I-II) and in ATTRwt [2].

Open Access This article is licensed under a Creative Commons Attribution 4.0 International License, which permits use, sharing, adaptation, distribution and reproduction in any medium or format, as long as you give appropriate credit to the original author(s) and the source, provide a link to the Creative Commons licence, and indicate if changes were made. The images or other third party material in this article are included in the article's Creative Commons licence, unless indicated otherwise in a credit line to the material. If material is not included in the article's Creative Commons licence and your intended use is not permitted by statutory regulation or exceeds the permitted use, you will need to obtain permission directly from the copyright holder. To view a copy of this licence, visit http://creativecommons.org/licenses/by/4.0/.

\section{References}

1. Ruberg RL, Grogan M, Hanna M, et al. Transthyretin amyloid cardiomyopathy: JACC state-of-the-art review. JAm Coll Cardiol. 2019;73(22):2872-91.

2. Maurer MS, Schwartz JH, Gundapaneni B, et al. Tafamidis treatment for patients with transthyretin amyloid cardiomyopathy. NEngl J Med. 2018;379(11):1007-16. 